\title{
Can a mononuclear iron(III)superoxo active site catalyze the decarboxylation of dodecanoic acid in UndA to produce biofuels?
}

DOI:

10.1002/chem.201903783

\section{Document Version}

Accepted author manuscript

Link to publication record in Manchester Research Explorer

Citation for published version (APA):

Lin, Y., Staczak, A., Manchev, Y., Straganz, G., \& De Visser, S. (2019). Can a mononuclear iron(III)superoxo active site catalyze the decarboxylation of dodecanoic acid in UndA to produce biofuels? Chemistry - A European Journal. https://doi.org/10.1002/chem.201903783

Published in:

Chemistry - A European Journal

\section{Citing this paper}

Please note that where the full-text provided on Manchester Research Explorer is the Author Accepted Manuscript or Proof version this may differ from the final Published version. If citing, it is advised that you check and use the publisher's definitive version.

\section{General rights}

Copyright and moral rights for the publications made accessible in the Research Explorer are retained by the authors and/or other copyright owners and it is a condition of accessing publications that users recognise and abide by the legal requirements associated with these rights.

\section{Takedown policy}

If you believe that this document breaches copyright please refer to the University of Manchester's Takedown Procedures [http://man.ac.uk/04Y6Bo] or contact uml.scholarlycommunications@manchester.ac.uk providing relevant details, so we can investigate your claim.

\section{OPEN ACCESS}




\title{
Can a mononuclear iron(III)-superoxo active site catalyze the decarboxylation of dodecanoic acid in UndA to produce biofuels?
}

\author{
Yen-Ting Lin, ${ }^{[a, e]}$ Agnieszka Stańczak, ${ }^{[a, b, e]}$ Yulian Manchev, ${ }^{[a]}$ Grit D. Straganz, ${ }^{[\mathrm{c}, \mathrm{d}]}$ and Sam P. de \\ Visser $^{*[a]}$
}

\begin{abstract}
Decarboxylation of fatty acids is an important reaction in cell metabolism, but also has potential in biotechnology for the biosynthesis of hydrocarbons as biofuels. The recently discovered nonheme iron decarboxylase UndA is involved in the biosynthesis of 1-undecene from dodecanoic acid and using X-ray crystallography was assigned to be a mononuclear iron species. However, the work was contradicted by spectroscopic studies that suggested UndA to be more likely a dinuclear iron system. To resolve this controversy we decided to pursue a computational study on the reaction mechanism of fatty acid decarboxylation by UndA using iron(III)superoxo and diron(IV)-dioxo models. We tested several models with different protonation states of active site residues. Overall, however, the calculations imply that mononuclear iron(III)-superoxo is a sluggish oxidant of hydrogen atom abstraction reactions in UndA and will not be able to activate fatty acid residues by decarboxylation at room temperature. By contrast, a diiron-dioxo complex reacts with much lower hydrogen atom abstraction barriers and hence is a more likely oxidant in UndA.
\end{abstract}

structural features and utilize $\alpha$-ketoglutarate as a co-substrate to form an iron(III)-superoxo that is converted into a high-valent iron(IV)-oxo species. The latter performs the oxygen atom transfer reactions to substrate.

Structurally, nonheme iron dioxygenases have specific ligand features where the metal is often bound to the side chains of two histidine amino acid groups and a carboxylate group of either Asp or Glu, typically in a 2-His/1-Asp facial ligand motif. ${ }^{[6]}$ Interestingly, a few nonheme iron dioxygenases have ligand motifs deviating from 2-His/1-Asp but why that is and how it affects the reactivity is poorly understood. In particular, several thiolate utilizing nonheme iron dioxygenases contain a 3 -His ligand motif including the ergothioneine biosynthesis enzyme EgtB and cysteine dioxygenase (CDO). ${ }^{[7,8]}$ In both of these enzymes an iron(III)-superoxo species is formed after dioxygen binding, which reacts with substrate directly through oxygen atom transfer.

\section{Introduction}

Nonheme iron dioxygenases are important enzymes in the human body responsible for vital functions for human health. ${ }^{[1]}$ They are involved in biodegradation as well as biosynthesis reactions, such as the catabolism and regulation of toxic cysteine in the body and the biosynthesis of the amino acid R-4hydroxyproline from proline. ${ }^{[2]}$ The latter is an essential product for collagen crosslinking processes in the body and hence affects aging processes. ${ }^{[3]}$ AlkB, another nonheme iron dioxygenase, is responsible for the DNA base repair mechanisms that convert alkylated DNA bases back to their nonalkylated forms. ${ }^{[4]}$ In plants, many signaling molecules linked to flowering and fruit ripening are synthesized by nonheme iron dioxygenases. ${ }^{[5]}$ As such, the nonheme iron dioxygenases have varied functions in biology and are highly selective. Nevertheless, many of these nonheme iron dioxygenases have similar

[a] Mr Y.-T. Lin, Miss A. Stanczak, Mr Y. Manchev, and Dr S. P. de Visser,

The Manchester Institute of Biotechnology and Department of Chemical Engineering and Analytical Science, The University of Manchester

131 Princess Street, Manchester, M1 7DN, United Kingdom. sam.devisser@manchester.ac.uk

[b] Miss A. Stanczak

Silesian University of Technology, Faculty of Chemistry, ks. Marcina Strzody 9, 44-100 Gliwice, Poland

[c] Dr G.D. Straganz,

Graz University of Technology, Institute of Biochemistry, Petergasse 12, A-8010 Graz, Austria

[d] Dr G.D. Straganz,

current address: bisy Petersgasse 14, A-8010 Graz, Austria

[e] YTL and AS contributed equally.

Supporting information for this article is given via a link at the end of the document.

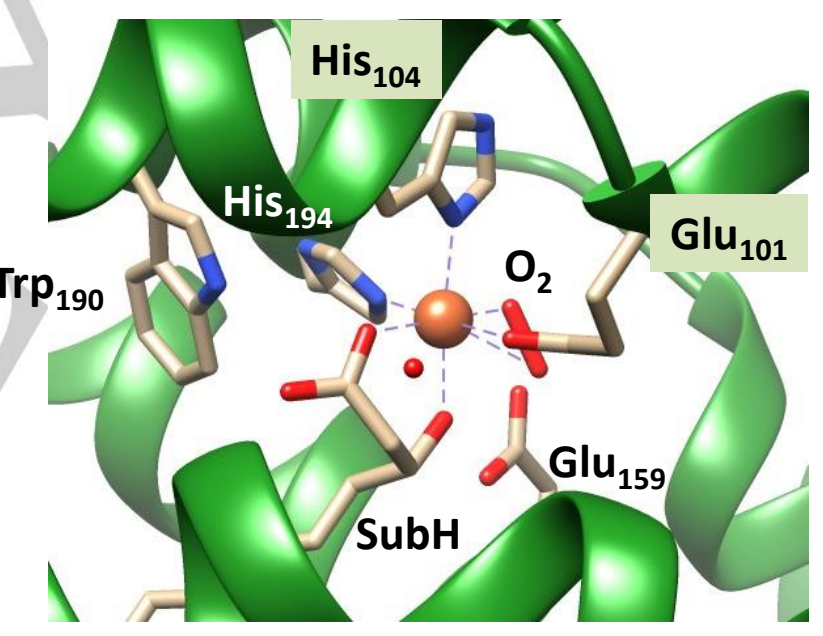

Figure 1. Active site structure of substrate-bound UndA as taken from the 4 WX0 pdb file.

The recently discovered nonheme iron decarboxylase UndA is an 1-undecene biosynthesis enzyme and is able to convert medium-chain fatty acids into terminal olefins. ${ }^{[9]}$ A crystal structure was determined that revealed a mononuclear iron atom that is ligated to the protein through linkages with $\mathrm{His}_{104}, \mathrm{His}_{194}$ and Glu $_{101}$ (Figure 1). Based on the crystallographic and biochemical studies a catalytic cycle was proposed for the conversion of medium-chain fatty acids (such as dodecanoic acid or lauric acid) to terminal olefins. They proposed direct binding of the substrate to the iron with its carboxylate group followed by a hydrogen atom abstraction reaction by the iron(III)superoxo species. The mechanistic proposal for $U n d A^{[9]}$ resembles the ones proposed for substrate activation in isopenicillin $\mathrm{N}$ synthase (IPNS) ${ }^{[10]}$ and 1-aminocyclopropane-1carboxylic acid oxidase. ${ }^{[11]}$ Both of these enzymes form an 
iron(III)-superoxo species that abstract a hydrogen atom from substrate through a rate-determining reaction step.

Figure 1 displays the active site structure of UndA as taken from the $4 \mathrm{WX0}$ protein databank (pdb) file. ${ }^{[9]}$ As can be seen the iron(II) is bound to the protein through interactions with $\mathrm{Glu}_{101}$, $\mathrm{His}_{104}$ and $\mathrm{His}_{194}$ and binds the substrate analog $\alpha$-hydroxydodecanoic acid through the carboxylate group. In contrast to other nonheme iron dioxygenases, such as taurine/ $\alpha$ ketoglutarate dioxygenase and prolyl-4-hydroxylase,${ }^{[12]}$ the 2His/1-Asp ligands do not form a facial triad but Glu 101 in UndA is trans to $\mathrm{His}_{194}$ instead. The active site also has dioxygen (or superoxo) bound, which is in hydrogen bonding distance to the carboxylate group of $\mathrm{Glu}_{159}$. The active site is completed by a nearby $\operatorname{Trp}$ residue $\left(\operatorname{Trp}_{190}\right)$ parallel to the $\mathrm{His}_{194}$ imidazole ring through $\pi$-stacking. As such there appears to be a network of hydrogen bonding interactions that stabilize the active site structure.

Recently, a controversy has arisen regarding the mechanism of UndA with substrates. Thus, Makris et $\mathrm{al}^{13]}$ did a similarity match with other enzymes and found the UndA protein to be close in structure to several diiron enzymes. In particular, nearby the iron atom in the crystal structure coordinates of $4 \mathrm{WXO}$ they found a small pocket that could fit a second iron atom. Moreover, that pocket contains several viable residues for binding this second iron atom, namely $\mathrm{His}_{201}$ and $\mathrm{Glu}_{159}$. They, therefore, suggested that UndA is more likely to be a diiron decarboxylase instead and reported spectroscopic evidence in support. ${ }^{[13]}$ To resolve the dichotomy, and find out whether mononuclear iron center in UndA would be able to transform dodecanoic acid into undecene and $\mathrm{CO}_{2}$, we decided to do a computational study into the reactivity of a mononuclear iron(III)-superoxo model of UndA with hexanoic acid as substrate using active site models with various protonation states. Our work shows that a mononuclear iron(III)-superoxo species in UndA is unlikely to be the oxidant as high energy reaction barriers for substrate activation are found for the mononuclear models, which would imply sluggish hydrogen atom abstraction ability at room temperature. For a diiron-dioxo model structure; however, much lower hydrogen atom abstraction barriers are found, hence is a more likely active species of UndA.

\section{Results and Discussion}

To understand the reaction mechanism of UndA and find out whether it is more likely mononuclear or dinuclear iron, we decided to run a series of density functional theory calculations on active site models. In addition, we investigated the reactivity patterns for the Glu101His mutant of the mononuclear iron system that gives a 3-His metal binding pattern. Cluster models have been extensively used in enzyme mechanism research and were successfully applied previously to understand the catalysis by heme monoxygenase and nonheme iron dioxygenase studies. ${ }^{[14]}$

We created several active site models based on the crystal structure coordinates obtained from the $4 \mathrm{WXO} \mathrm{pdb}$ file. ${ }^{\left[{ }^{[9}\right.}$ Scheme 1 displays the key features of our models and the mechanism explored with definitions of the labels of the various structures. Firstly, we created several mononuclear iron models of the active site of UndA, namely models A and B. These models included all first sphere ligands of the metal, i.e. Glu $\mathbf{u}_{101}$, $\mathrm{His}_{104}$ and $\mathrm{His}_{194}$, whereby the histidine groups were abbreviated to methyl-imidazole and the glutamic acid groups by acetate. The substrate was shortened to hexanoic acid and $\operatorname{Trp}_{190}$ by methyl-indole. We also included an active site water molecule in the model that was seen to form a hydrogen bond between the carboxylate group of substrate and the Trp 190 group. Nearby the dioxygen binding site is a carboxylic acid group of $\mathrm{Glu}_{159}$, which we considered to be deprotonated (model A) or protonated (model B) and was included in the model as acetate/acetic acid, respectively. These models had overall charge -1 (model $\mathbf{A})$ and 0 (model B) and were calculated with odd multiplicity. An alternative model (model A1), where the Glu ${ }_{101}$ was mutated for His was also explored and had overall charge 0 and explored the effect of the first-coordination sphere of iron ligands on the reactivity.

Finally, we created a dinuclear iron complex based on the suggestions of Makris et $\mathrm{al}^{\left[{ }^{[13]}\right.}$ whereby a second iron atom is linked to $\mathrm{Glu}_{101}, \mathrm{Glu}_{159}$ and $\mathrm{His}_{201}$ and bridged by two oxo groups in a $\mathrm{Fe}^{\mathrm{IV}}{ }_{2} \mathrm{O}_{2}$ diamond conformation (model C). In this model the peptide chain linking $\mathrm{Glu}_{101}$ and $\mathrm{His}_{104}$ was incorporated in the model with the $\mathrm{Leu}_{102}$ and $\mathrm{Asn}_{103}$ residues abbreviated to Gly. Similarly, the chain linking $\mathrm{Asp}_{199}$ and $\mathrm{His}_{201}$ was included with $\mathrm{Ala}_{200}$ shortened to Gly. The diiron model had overall neutral charge and was calculated in the ferromagnetic $(5 / 2,5 / 2)$ diiron and antiferromagnetic $(5 / 2,-5 / 2)$ diiron spin states.

The general reaction mechanism calculated starts from our reactant structure $(\mathbf{R e})$ and follows the hydrogen atom abstraction of the $\beta$-position via transition state TS1 to form the radical intermediate IM1. Next, the $\mathrm{C}_{\alpha}-\mathrm{C}_{\beta}$ bond in the substrate breaks via transition state TS2 to form intermediate IM2. An electron transfer from $\mathrm{CO}_{2}^{-\bullet}$ to iron then releases $\mathrm{CO}_{2}$ and pentene via transition state TS3 to from products $\mathbf{P}$. For some models also hydrogen atom abstraction from the $\mathrm{C}_{\alpha}$-position of substrate was explored as identified with a subscript after the label.

\section{Mononuclear iron model A.}

We started the work with calculations of the mononuclear iron(III)-superoxo species with a starting structure that closely resembles the crystal structure coordinates. The lowest energy singlet, triplet, quintet and septet spin states for Model A were geometry minimized and the optimized structures are given in Figure 2. Interestingly, the septet spin state is the ground state with the triplet and quintet spin states higher in energy by 2.7 and $12.1 \mathrm{kcal} \mathrm{mol}^{-1}$. We also tested the singlet spin state but found it well higher by more than $30 \mathrm{kcal} \mathrm{mol}^{-1}$, therefore, this spin state surface was not pursued further. The spin-state ordering of the iron(III)-superoxo complexes obtained here is unusual as a quintet spin ground state is normally seen for analogous complexes, ${ }^{[15]}$ although for CDO an open-shell singlet spin state reactant was found using $\mathrm{QM} / \mathrm{MM}^{\left[{ }^{[16]}\right.}$ The latter is probably the result of differences in metal coordination that stabilizes the low-spin state. 

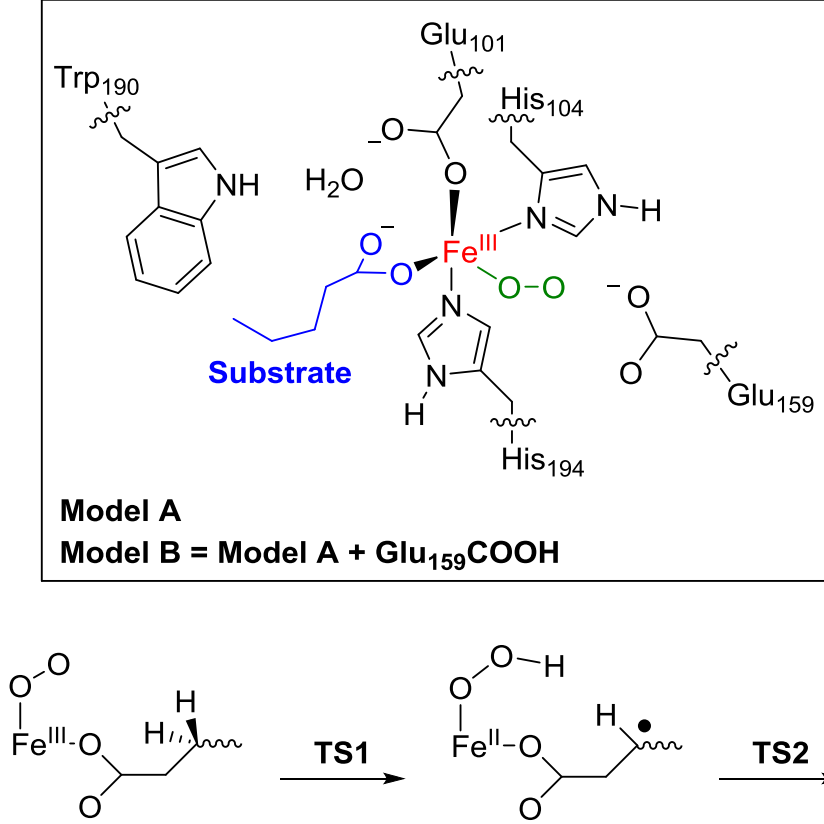

$\operatorname{Re}$

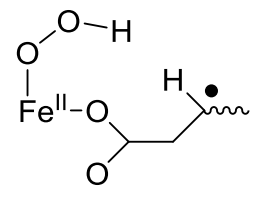

IM1
TS2<smiles>[AsH2]</smiles><smiles>C=CCCCCCCCCCO</smiles>

IM2
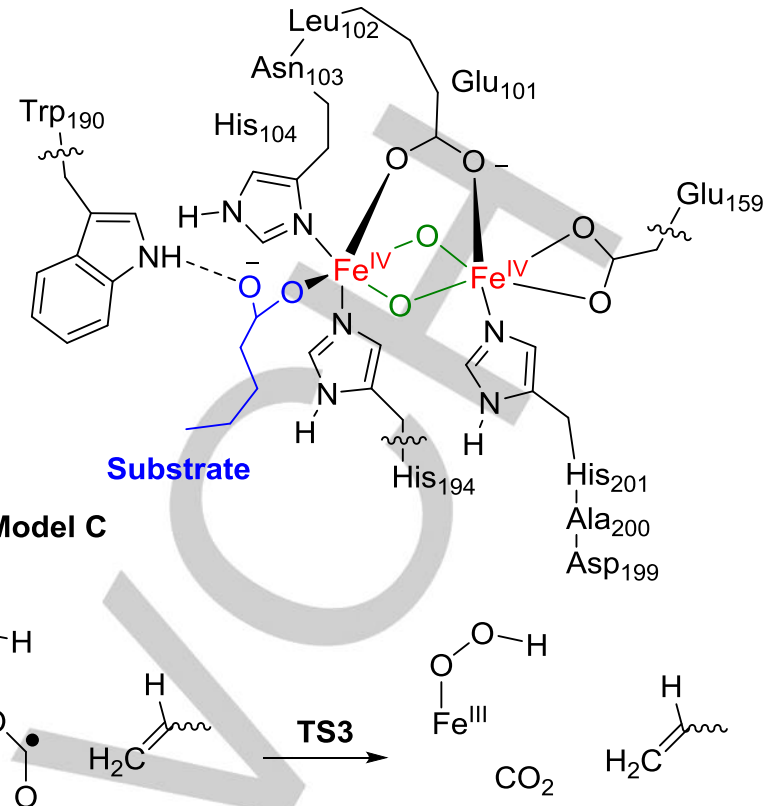

$\mathbf{P}$

Scheme 1. DFT models investigated in this work and reaction mechanism with labelling of structures.

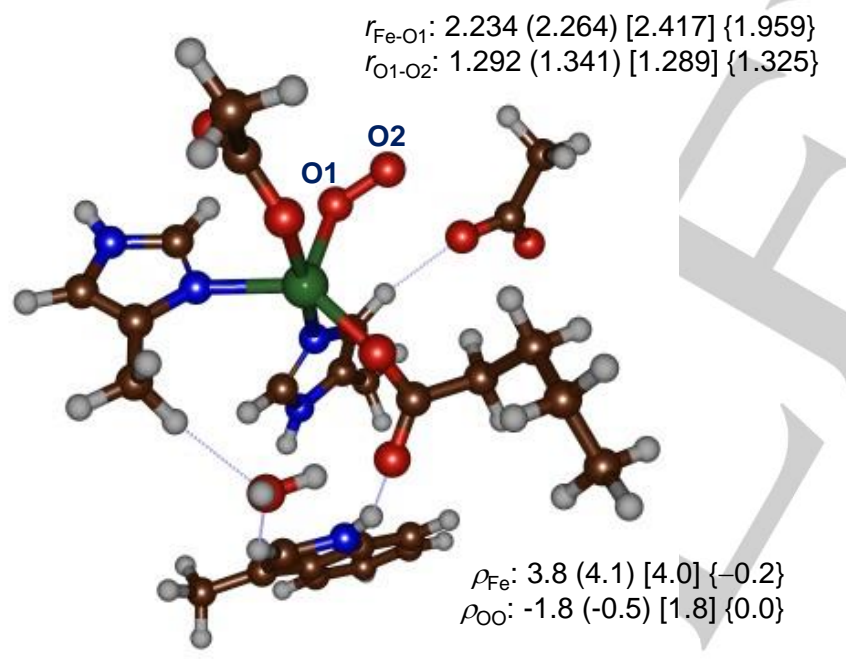

$\Delta \mathrm{E}+\mathrm{ZPE}=2.7(12.1)[0.0]\{36.9\}$

${ }^{3} \operatorname{Re}_{\mathbf{A}}\left({ }^{5} \mathbf{R e}_{\mathrm{A}}\right)\left[{ }^{7} \mathbf{R e}_{\mathrm{A}}\right]\left\{{ }^{1} \mathbf{R e}_{\mathrm{A}}\right\}$

Figure 2. UB3LYP/BS1 optimized geometries of ${ }^{1,3,5,7} \mathbf{R e}$ as obtained in Gaussian-09. Bond lengths are in angstroms, spin densities in atomic units and $\Delta \mathrm{E}+\mathrm{ZPE}$ values are in $\mathrm{kcal} \mathrm{mol}{ }^{-1}$ with solvent included.

Geometrically, in the triplet, quintet and septet spin states the $\mathrm{Fe}-\mathrm{O}$ distance in the iron(III)-superoxo species is relatively long, i.e. well over $2.2 \AA$ and as a result dioxygen retains a considerable amount of spin density (about 1.8 in the triplet and septet spin states of $\mathbf{R e}_{\mathbf{A}}$ ). Therefore, these structures should be seen as an iron(II)-dioxygen complex rather than iron(III)superoxo. Most likely this is caused by the hydrogen bonding interactions with the carboxylate group of $\mathrm{Glu}_{159}$ that pushes electron density from dioxygen to iron and prevents it from tautomerization into the iron(III)-superoxo form. All low-lying electronic states have four unpaired electrons on the metal and spin densities of 3.8, 4.1 and 4.0 on iron are found in ${ }^{3} \mathbf{R e}_{\mathbf{A}},{ }^{5} \mathbf{R e}_{\mathbf{A}}$ and ${ }^{7} \mathbf{R e}_{\mathrm{A}}$, respectively.

Subsequently, we investigated the reaction mechanism of substrate decarboxylation by the iron(III)-superoxo species on the lowest energy singlet, triplet, quintet and septet spin states of model A. The mechanism is distinct from heme decarboxylases, such as cytochrome P450 OleT JE. ${ }^{[17]}$ Studies on P450 OleT JE showed that it uses $\mathrm{H}_{2} \mathrm{O}_{2}$ on an iron heme and forms a high-valent iron(IV)-oxo heme cation radical active species called Compound I (Cpd I). ${ }^{[18]}$ Indeed, previous QM/MM studies of our group ${ }^{[19]}$ on the decarboxylation of fatty acids by the cytochrome $\mathrm{P} 450$ peroxygenase Ole $\mathrm{T}_{\mathrm{JE}}$ showed the reaction to start with hydrogen atom abstraction from the $\beta$-position of a long-chain fatty acid substrate by $\mathrm{Cpd} I$ and led to a subsequent barrierless decarboxylation quickly. Calculations starting with hydrogen atom abstraction from the $\mathrm{C}_{\alpha}-\mathrm{H}$ bond instead, however, were found to give substrate hydroxylation as sole products and no decarboxylation could be formed. As such a mixture of products was predicted for P450 OleT JE, which was confirmed by further studies that tested a range of substrates whereby short-chain fatty acids gave hydroxylation and desaturation products, whereas long-chain unbranched fatty acids produced terminal olefins and hydroxylated fatty acids. ${ }^{[20]}$ Interestingly, the experimental work of Zhang et $\mathrm{al}^{[9]}$ on UndA showed no evidence of hydrogen atom abstraction from the $C_{\alpha^{-}}$ position of substrate when those hydrogen atoms were replaced by deuterium. 


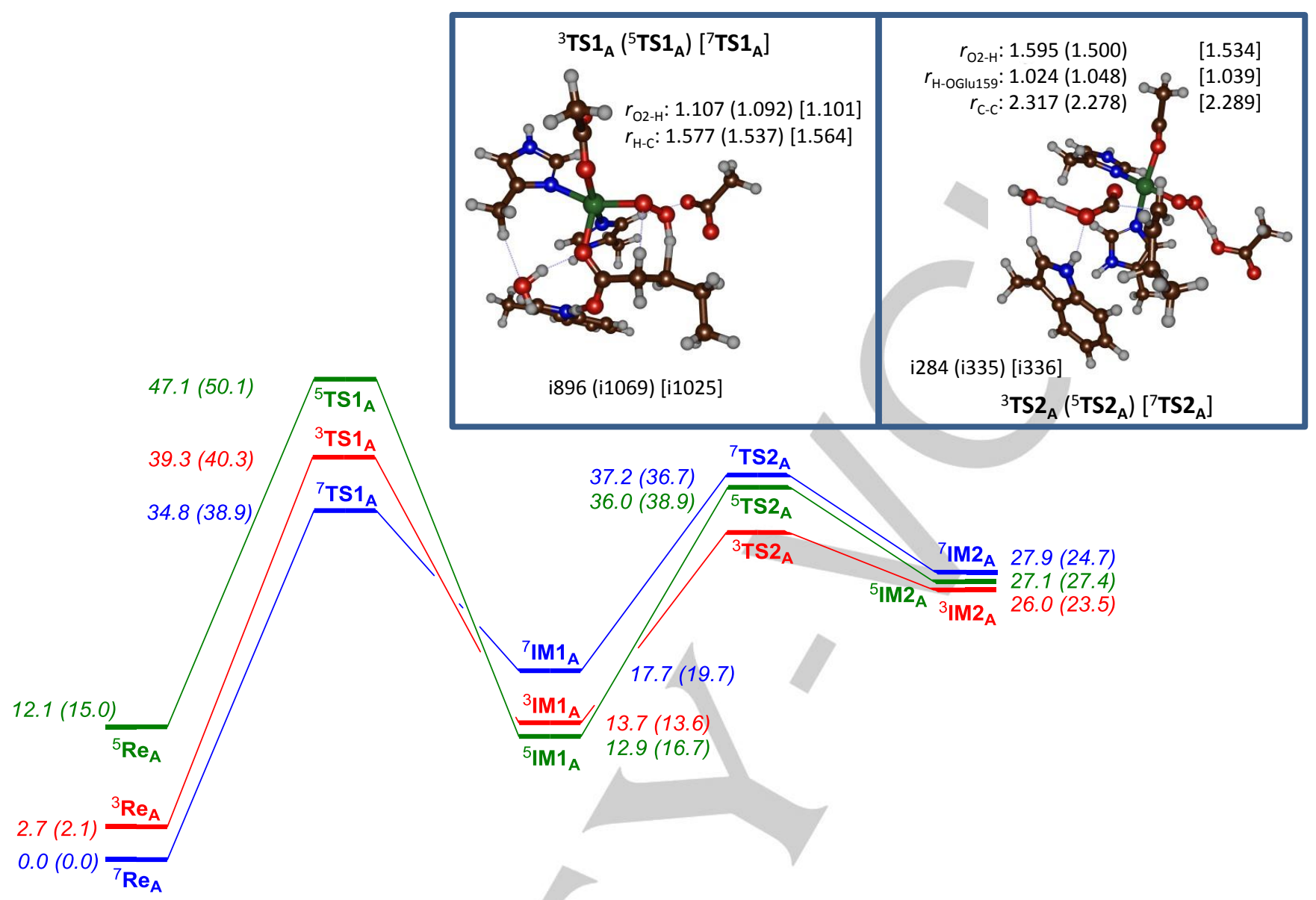

Figure 3. UB3LYP/BS2//UB3LYP/BS1+ZPE calculated potential energy profile of substrate decarboxylation by iron(III)-superoxo model A of UndA. Energies are in $\mathrm{kcal} \mathrm{mol}^{-1}$ with Gibbs free energies (in parenthesis) at $298 \mathrm{~K}$ with solvent, entropic and thermal corrections in parenthesis. Optimized geometries give bond lengths in angstroms and the imaginary frequency is in $\mathrm{cm}^{-1}$.

Clearly, UndA and P450 OleT JE react differently with long chain fatty acids and therefore we decided to study the mechanism of substrate activation by the iron(III)-superoxo species of an UndA model. Figure 3 displays the calculated reaction mechanism of hexanoic acid decarboxylation by the iron(III)-superoxo of UndA model $\mathbf{A}$ as calculated with DFT. The mechanism proceeds through multistate reactivity patterns on close-lying triplet, quintet and septet spin states as often seen for reactivity patterns of nonheme iron dioxygenases and nonheme iron model complexes. ${ }^{[21,22]}$

As the singlet spin reactant is high in energy, we decided not to explore this surface further. The hydrogen atom abstraction barrier is lowest on the septet spin state with a barrier of 34.8 $\mathrm{kcal} \mathrm{mol}^{-1}$. The triplet and quintet spin hydrogen atom abstraction barriers are 39.3 and $47.1 \mathrm{kcal} \mathrm{mol}^{-1}$ in energy and hence the spin state ordering in the transition states is the same as in the reactants. These barriers are relatively high in energy and would suggest a slow and possibly sluggish reaction mechanism for hydrogen atom abstraction. For comparison, in previous work on trends of hydrogen atom abstraction reactions by P450 Cpd I we found substantially lower energy barriers (well below $20 \mathrm{kcal} \mathrm{mol}^{-1}$ ) for typical aliphatic substrates, while for methane a value of $22.3 \mathrm{kcal} \mathrm{mol}^{-1}$ was found with the same methods and procedures as used here. ${ }^{[23]}$ As P450 Cpd I is not known to activate methane, our hydrogen atom abstraction barriers of Figure 3 implicate that an UndA model with an iron(III)-superoxo oxidant and nearby deprotonated $\mathrm{Glu}_{159}$ residue will not be able to activate fatty acids at room temperature.

The energetic landscape depicted in Figure 3 contradicts computational studies of several nonheme iron dioxygenases reported previously that gave efficient hydrogen atom abstraction by an iron(III)-superoxo. Thus, computational studies of Hirao et al. ${ }^{[2]}$ on 2-hydroxyethylphosphonate dioxygenase predicted a rate determining hydrogen atom abstraction barrier of $19.7 \mathrm{kcal} \mathrm{mol}^{-1}$ by a mononuclear nonheme iron(III)-superoxo complex. A similar conclusion was obtained by Morokuma et al. ${ }^{[25]}$ on isopenicillin $N$ synthase, who reported a $Q M / M M$ calculated hydrogen atom abstraction barrier of $14.6 \mathrm{kcal} \mathrm{mol}^{-1}$ by a quintet spin iron(III)-superoxo complex. Both of these studies had the metal bound in a facial 2-His/1-Asp ligand orientation, while the UndA model has the two carboxylate groups equatorial to each other. These differences in ligand coordination may affect the reactivity and the ability of the iron to abstract electrons. Clearly, the hydrogen atom abstraction barriers by nonheme iron(III)-superoxo complexes vary widely and must be dependent on first- and second-coordination 
sphere effects of the metal center. Therefore, we also explored alternative models and environmental effects.

Optimized geometries of the hydrogen atom abstraction transition states $\left({ }^{3,5,7} \mathbf{T S} 1_{\mathrm{A}}\right)$ are given in Figure 3. All hydrogen atom abstraction barriers $\left({ }^{3,5,7} \mathbf{T S} \mathbf{1}_{\mathbf{A}}\right)$ are product-like with short $\mathrm{O}-\mathrm{H}$ and long $\mathrm{C}-\mathrm{H}$ bonds: $\mathrm{O}-\mathrm{H}$ distances of 1.107 (1.092) [1.101] $\AA$ and $\mathrm{C}-\mathrm{H}$ distances of 1.577 (1.537) [1.564] $\AA$ are found for ${ }^{3} \mathrm{TS} 1_{\mathrm{A}}\left({ }^{5} \mathrm{TS} 1_{\mathrm{A}}\right)\left[{ }^{7} \mathbf{T S} 1_{\mathrm{A}}\right]$. Previous trends on hydrogen atom abstraction barriers by metal-oxo complexes showed that transition states with product-type geometries usually correlate with high energy transition states, ${ }^{[2,26]}$ as seen here. Although for isopenicillin-N-synthase (IPNS) product-like transition states were also found with either QM/MM and DFT cluster models, the $\mathrm{C}-\mathrm{H}$ distance was much shorter: $1.36 \AA$ using $\mathrm{QM} / \mathrm{MM}$ and $1.41 \AA$ for the DFT cluster model. ${ }^{[25,27]}$ Yet, the barriers for hydrogen atom abstraction by an iron(III)-superoxo complex of IPNS was only $9.3 \mathrm{kcal} \mathrm{mol}^{-1}$ for the DFT cluster model and 14.6 $\mathrm{kcal} \mathrm{mol}^{-1}$ with QM/MM. Consequently, nonheme iron(III)superoxo should be able to activate $\mathrm{C}-\mathrm{H}$ bonds of substrates and the fact that we do not see any reactivity in our model here must originate from the coordination environment of the metal center.

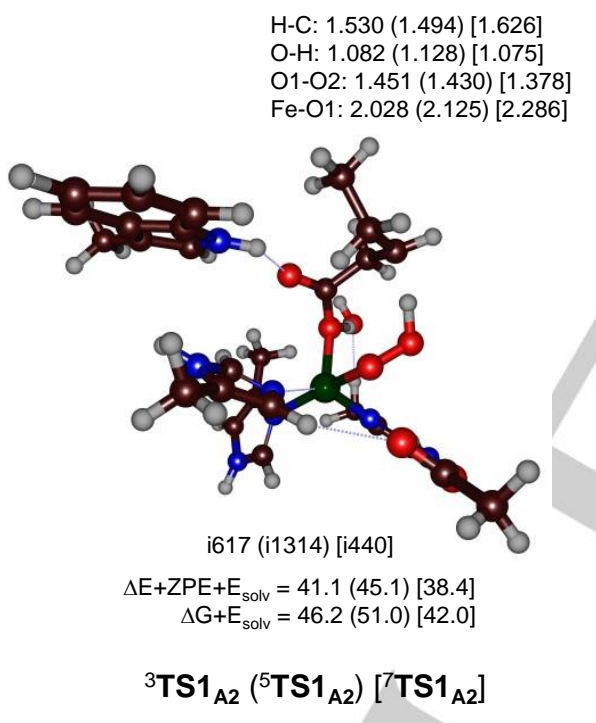

Figure 4. UB3LYP/BS2//UB3LYP/BS1+ZPE calculated hydrogen atom abstraction barriers by the iron(III)-superoxo model A2 of UndA. Energies are in $\mathrm{kcal} \mathrm{mol}^{-1}$ with Gibbs free energies at $298 \mathrm{~K}$ with solvent, entropic and thermal corrections in parenthesis. Optimized geometries give bond lengths in angstroms and the imaginary frequency in $\mathrm{cm}^{-1}$.

The hydrogen atom abstraction transition states are characterized with a large imaginary frequency of i896 (triplet), i1069 (quintet) and i1025 $\mathrm{cm}^{-1}$ (septet). These are typical values for hydrogen atom abstraction transition states and often implicate a large kinetic isotope effect when the transferring hydrogen atom is replaced by deuterium. ${ }^{[28]}$ Group spin densities of ${ }^{7} \mathbf{T S} 1_{\mathrm{A}}$, shows a drop in value on the dioxygen moiety from 1.78 in ${ }^{7} \mathbf{R e}_{\mathrm{A}}$ to 1.04 and accumulation of unpaired spin on the substrate moiety to 0.77 . A similar change is seen in the triplet spin pathway, where the dioxygen spin density rises from -1.77 in ${ }^{3} \mathbf{R} \mathbf{e}_{\mathrm{A}}$ to -1.00 in ${ }^{3} \mathbf{T S} \mathbf{1}_{\mathrm{A}}$, while the radical on the substrate has a value of -0.68 . Therefore, in our reactant complex the iron(II)dioxygen species picks up a hydrogen atom to form an iron(III)hydroperoxo complex. During the geometry optimization of ${ }_{1,3,5,7} \mathbf{I M} 1_{\mathrm{A}}$; however, the hydroperoxo species relays its proton to the carboxylic acid group of $\mathrm{Glu}_{159}$. Moreover, the group spin densities give a single unpaired electron of the dioxygen species and hence these structures should be seen as iron(III)-superoxo complexes.

In the next stage of the reaction the $\mathrm{C}_{\alpha}-\mathrm{C}_{\beta}$ bond of the substrate cleaves via a transition state $\mathbf{T S} \mathbf{2}_{\mathrm{A}}$ to form intermediate IM2 $\mathbf{2}_{\mathrm{A}}$. In all $\mathbf{T S 2}_{\mathrm{A}}$ transition states significant radical character on the substrate remains, which means the $\mathrm{C}_{\alpha}-\mathrm{C}_{\beta}$ bond breakage gives $\mathrm{CO}_{2}^{-\bullet}$ and terminal olefin. At the same time, the spin density on the iron-hydroperoxo unit is very similar in $\mathbf{I M} \mathbf{1}_{\mathrm{A}}$ and $\mathbf{I M} \mathbf{2}_{\mathrm{A}}$ for all spin states and confirms that the electron transfer from $\mathrm{CO}_{2}^{-\bullet}$ to iron has not happened at this stage and therefore is not simultaneous to the $\mathrm{C}_{\alpha}-\mathrm{C}_{\beta}$ bond cleavage. On the quintet and septet spin state surfaces the barriers for decarboxylation via TS2 ${ }_{\mathrm{A}}$ are very large and implicate slow reaction steps. Overall, the calculations of substrate decarboxylation by a mononuclear iron(III)-superoxo species of UndA model A implicate an unrealistic high energy pathway with barriers that indicate a very slow reaction process. To find out whether mononuclear iron(III)superoxo can react with fatty acids via decarboxylation reactions, we decided to explore alternative model structures.

\section{Mononuclear iron model A2}

To gain insight into the first-coordination sphere effects of ligands in mononuclear iron UndA, we tested an UndA mutant structure where the $\mathrm{Glu}_{101}$ residue is replaced by His, i.e. the Glu101His mutant or model A2. The iron(III)-superoxo reactant of model $\mathbf{A 2}$ has a septet spin ground state that is well separated from the nearest quintet, triplet and singlet spin states by $11.1,43.8$ and $54.0 \mathrm{kcal} \mathrm{mol}{ }^{-1}$. The hydrogen atom abstraction barriers on each of these spin state surfaces are given in Figure 4. All of them are high in energy and range from 38.4 (for ${ }^{7} \mathrm{TS}_{\mathrm{A} 2}$ ) to 45.1 (for ${ }^{5} \mathrm{TS}_{\mathrm{A} 2}$ ) $\mathrm{kcal} \mathrm{mol}^{-1}$. As such the mutant with 3-His metal coordination as well as wild-type with 2His/1-Glu coordination both are sluggish oxidants of hydrogen atom abstraction reactions. For this particular model, the change in metal coordination from an anionic ligand (Glu) to a neutral ligand (His) has little effect on the kinetics of the reaction with substrate.

The hydrogen atom abstraction transition states for the 3-His mutant of mononuclear iron UndA are given in Figure 4. Similarly, to those given above in Figure 3 for model $\mathbf{A}$ also for model $\mathbf{A} 2$ the transition states are late with long $\mathrm{C}-\mathrm{H}$ and short $\mathrm{O}-\mathrm{H}$ distances for ${ }^{3,5,7} \mathbf{T S} \mathbf{1}_{\mathrm{A} 2}$. The imaginary frequencies are considerably smaller in the triplet and septet spin states but still correspond to a hydrogen atom transfer from substrate to superoxo group. In conclusion, the first-coordination sphere of ligands, be it 2-His/1-Glu or 3-His, in UndA gives high barriers for hydrogen atom abstraction and therefore, the system appears to have the wrong coordination environment for efficient hydrogen atom abstraction from substrate. 


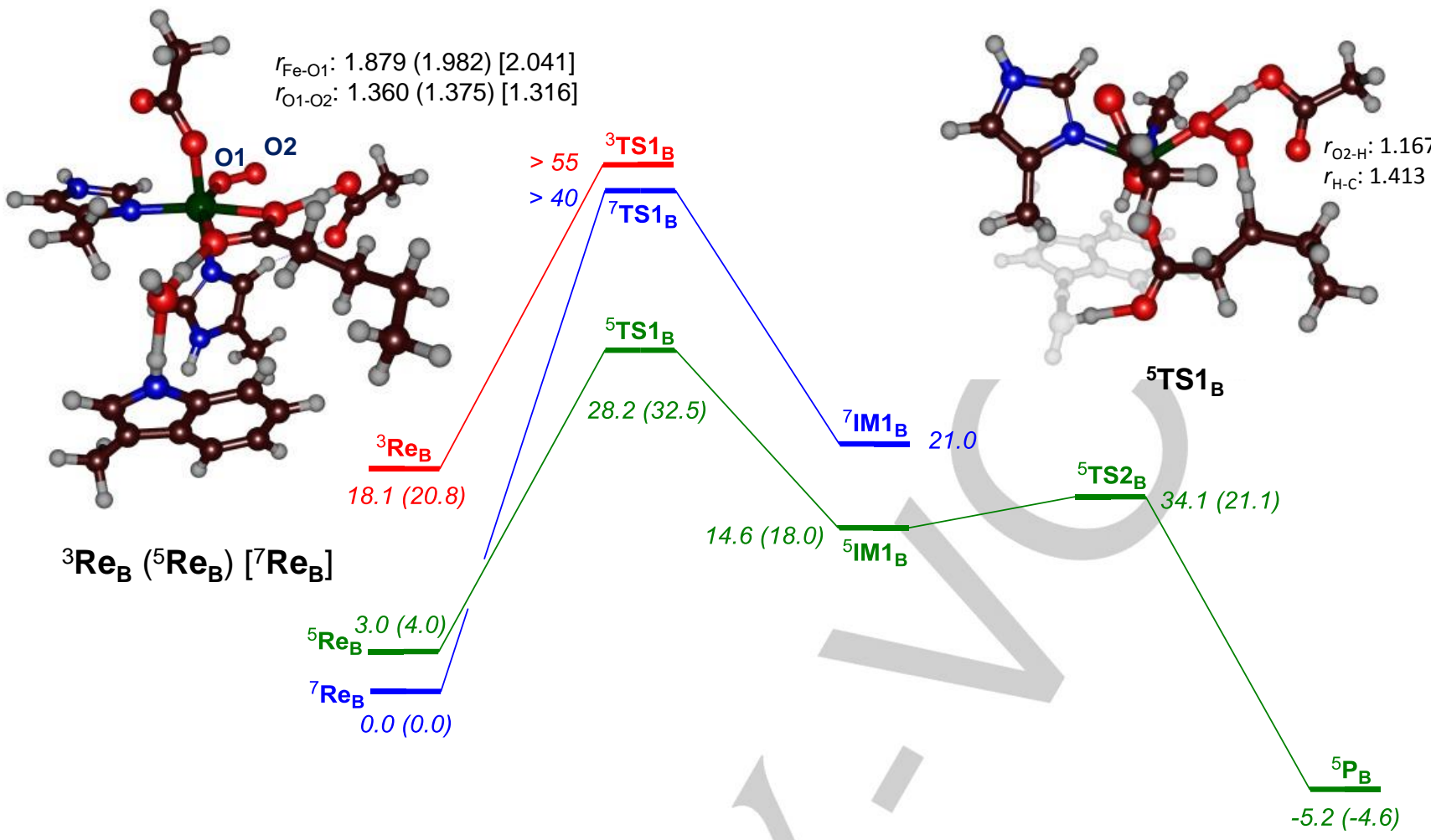

Figure 5. UB3LYP/BS2//UB3LYP/BS1+ZPE calculated Gibbs free energy profile of substrate decarboxylation by iron(III)-superoxo model B of UndA. Energies are in $\mathrm{kcal} \mathrm{mol}^{-1}$ with Gibbs free energies (in parenthesis) at 298K with solvent, entropic and thermal corrections in parenthesis. Optimized geometries give bond lengths in angstroms.

\section{Mononuclear iron model B}

To test whether the second coordination sphere affects the structure and reactivity of a mononuclear iron UndA model, we expanded our model and added a proton to the carboxylate group of $\mathrm{Glu}_{159}$, i.e. investigated model B. We started with the iron(III)-superoxo reactant complexes and calculated them in the lowest energy triplet, quintet and septet spin states The septet spin state $\left({ }^{7} \mathbf{R e}_{\mathrm{B}}\right)$ is still the ground state, but the quintet spin state $\left({ }^{5} \mathbf{R e}_{\mathrm{B}}\right)$ is now the nearest one by $3.0 \mathrm{kcal} \mathrm{mol}{ }^{-1}$, while the triplet spin state $\left({ }^{3} \mathbf{R e}_{\mathrm{B}}\right)$ has gone up to $18.1 \mathrm{kcal} \mathrm{mol}{ }^{-1}$.

Therefore, the second-coordination sphere has a strong effect on the spin state energies and affects the ordering and relative energies. One of the key effects seen in the optimized reactant structures of $\mathbf{R e}_{\mathrm{B}}$, Figure 5, is the hydrogen bond of the proton of $\mathrm{Glu}_{159}$ with the carboxylate group of the fatty acid substrate. By contrast, the Glu ${ }_{159}$ group in model A (Figure 2) hydrogen bonds with a histidine group instead. As such there has been some structural reorganization in the active site and the chargestabilization of $\mathrm{Glu}_{159}$ should influence the electronic configuration of the first-coordination sphere atoms. Note also that the substrate carboxylate is now bidentate coordination to iron, while it has single coordination in model $\mathbf{A}$.

Next, we calculated the hydrogen atom abstraction from the $\mathrm{C}_{\alpha}-$ $\mathrm{H}$ and $\mathrm{C}_{\beta}-\mathrm{H}$ positions of the substrate by ${ }^{3,5,7} \mathbf{R e}_{\mathrm{B}}$ and the obtained potential energy landscape is given in Figure 5. The quintet spin hydrogen atom abstraction transition state $\left({ }^{5} \mathbf{T S} 1_{B}\right)$ has a Gibbs free energy of activation $\Delta \mathrm{G}^{\ddagger}=32.5 \mathrm{kcal} \mathrm{mol}^{-1}$ with respect to ${ }^{7} \mathbf{R}_{\mathrm{B}}$ reactants. Although, the barrier has dropped considerably in energy with respect to the non-protonated species, i.e. $\Delta \mathrm{G}^{\ddagger}=32.5 \mathrm{kcal} \mathrm{mol}^{-1}$ for model $\mathbf{B}$ vs $47.1 \mathrm{kcal} \mathrm{mol}^{-1}$ for model $\mathbf{A}$; it is still very high for a hydrogen atom abstraction barrier. The structure has a short $\mathrm{O}-\mathrm{H}$ distance of $1.167 \AA$ and a relatively long $\mathrm{C}-\mathrm{H}$ distance of $1.413 \AA$ and hence, it is a late transition state, but not as early as ${ }^{5} \mathbf{T S} \mathbf{1}_{\mathrm{A}}$ that has an even longer $\mathrm{C}-\mathrm{H}$ distance.

Although we managed to optimize a transition state geometry for ${ }^{5} \mathbf{T S} 1_{B, \alpha}$, the geometry scans on the triplet and septet spin state showed high reaction barriers and were discarded. The subsequent $\mathrm{C}_{\alpha}-\mathrm{C}_{\beta}$ cleavage barrier is well over $90 \mathrm{kcal} \mathrm{mol}^{-1}$ and therefore, $\alpha$-hydrogen atom abstraction will not lead to decarboxylation of fatty acids. We also attempted a proton transfer from $\mathrm{Glu}_{159}-\mathrm{COOH}$ to iron(III)-superoxo to form an ironhydroperoxo complex. However, the constraint geometry scan for this pathway identified a high-energy process, hence is unfeasible under room temperature conditions.

Overall the calculations on mononuclear iron models of UndA show that iron(III)-superoxo species are weak oxidants of hydrogen atom abstraction processes. This may have to do with the ligand coordination in UndA, which does not have a facial 2His/1-Glu but the Glu trans to one of the His groups. By contrast, isopenicillin $\mathrm{N}$ synthase with a facial 2-His/1-Asp ligand coordination reacts by hydrogen atom abstraction from substrate with relatively low-energy barriers. Therefore, it appears that the ligand coordination in UndA is not correctly set up for hydrogen atom abstraction processes and our DFT cluster models rule out mononuclear iron as an oxidant that triggers the decarboxylation of dodecanoic acid in UndA. 


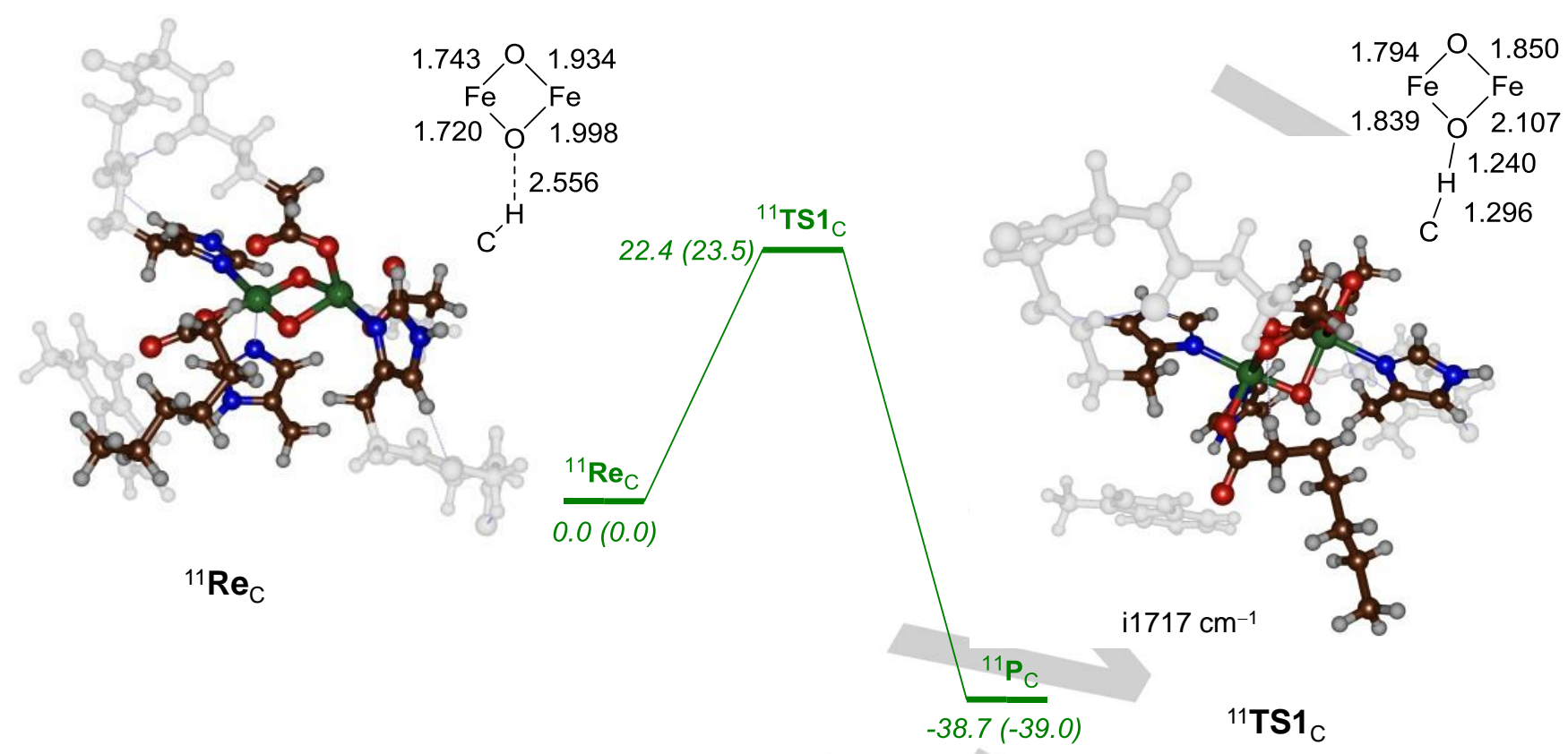

Figure 6. UB3LYP/BS2//UB3LYP/BS1+ZPE calculated energy profile of substrate decarboxylation by diiron(IV)-dioxo model C of UndA. Energies are in kcal mol ${ }^{-1}$ with Gibbs free energies (in parenthesis) at 298K with solvent, entropic and thermal corrections in parenthesis. Optimized geometries give bond lengths in angstroms and the imaginary frequency in $\mathrm{cm}^{-1}$.

Subsequently, we explored the effect of the ligand environment, i.e. a facial 2-His/1-Glu ligand coordination, on the reactivity with respect to that seen for model $\mathbf{A}$. To this end, we created two final models of a hypothetical nonheme iron(III)-superoxo model with a facial 2-His/1-Glu coordination system: models D and D2 (Supporting Information Figures 22 and 23). The reactant was optimized in the quintet spin state and a transition state for hydrogen atom abstraction was searched through an initial constraint geometry optimization. However, upon close approach of peroxo on the the $\mathrm{C}_{\beta}-\mathrm{H}$ position, the superoxo group dissociates from the iron center leading to high energy hydrogen atom abstraction pathways.

Consequently, this small model had too much freedom for the superoxo group and weakened its interaction with iron. Hence the small model with facial 2-His/1-Glu coordination system also did not lead to a viable hydrogen atom abstraction pathway from a fatty acid substrate. It may very well be that the substrate binding pocket in IPNS is much tighter than the one used in model $\mathbf{D}$ and prevents release of dioxygen from the iron center. A tight binding and positioning of oxidant and substrate should bring the two closely together in an ideal conformation for catalysis. Nevertheless, our calculations on various models of the mononuclear iron(III)-superoxo species of UndA show little evidence that hydrogen atom abstraction from substrate as a viable reaction mechanism. Therefore, we explored alternative diiron models instead.

\section{Dinuclear iron model C}

As mononuclear iron(III)-superoxo models of UndA appear to give high energy hydrogen atom abstraction transition states from aliphatic groups, we considered the alternative diiron species as an oxidant. Therefore, we created a diiron(IV)-dioxo active species from the UndA crystal structure coordinates by manually inserting a second iron into the cluster model and by linking this metal to nearby protein residues as suggested by Makris et al. ${ }^{[13]}$

A full geometry optimization of this reactant complex $\left({ }^{11} \mathbf{R e}_{\mathrm{C}}\right)$ is shown in Figure 6. The diiron-dioxo is in a diamond core although the two sets of iron-oxo distances are not equal. Thus, $\mathrm{Fe1}$, i.e. the metal that binds substrate, forms short interactions with the two oxygen bridges (1.720 and $1.743 \AA$ ), while Fe2 is further displaced from the bridging oxygen atoms (at distances of 1.934 and $1.998 \AA$ ). In the reactant structure, the $\mathrm{C}_{\beta}-\mathrm{H}$ bond of the substrate points towards one of the bridging oxygen atoms at a distance of $2.556 \AA$. In this particular orientation, therefore, the positioning of the $\mathrm{C}_{\beta}-\mathrm{H}$ bond of substrate is ideal for hydrogen atom abstraction.

To investigate the ability of ${ }^{11} \mathbf{R e}_{\mathrm{C}}$ to abstract a hydrogen atom from the $\mathrm{C}_{\beta}-\mathrm{H}$ position of substrate, we calculated the transition state structure. A hydrogen atom abstraction barrier of $\Delta \mathrm{E}^{\ddagger}+$ $\mathrm{ZPE}=22.4 \mathrm{kcal} \mathrm{mol}^{-1}$ is found. Even though this is a relatively high barrier in comparison to previous enzymatic reaction mechanisms, where typical barriers of $10-15 \mathrm{kcal} \mathrm{mol}^{-1}$ were found..$^{[14,21,24-27,29]}$ Our calculated reaction barrier would correspond to slow but doable reactivity at room temperature. As a matter of fact the experimental work of Zhang et al. ${ }^{[9]}$ report a slow reaction process for substrate conversion by UndA in agreement with the high reaction barrier reported in Figure 6 .

The hydrogen atom abstraction barrier has a large imaginary frequency of $i 1717 \mathrm{~cm}^{-1}$, which is well higher than those reported above for models $\mathbf{A}$ and $\mathbf{A} 2$. Consequently, the barrier will be narrow and sharp and will be highly dependent on quantum chemical tunneling. The transition state is relatively central with almost equal $\mathrm{C}-\mathrm{H}$ and $\mathrm{O}-\mathrm{H}$ distances of 1.296 and $1.240 \AA$, respectively. After the hydrogen atom abstraction, the system relaxes to a radical intermediate IM1, which is a shallow 
minimum and followed by $\mathrm{C}_{\alpha}-\mathrm{C}_{\beta}$ bond cleavage of the substrate to split off $\mathrm{CO}_{2}$ and give 1-pentene products without a stable intermediate IM2. Therefore, the process past the transition state, will quickly lead to final products.

The calculations on the diiron(IV)-dioxo model of UndA and its reaction with hexanoic acid shows that diron complexes can activate fatty acid substrates at room temperature. A cluster model shows that substrate binds in an ideal position for $\mathrm{C}_{\beta}-\mathrm{H}$ hydrogen atom abstraction by a diiron(IV)-dioxo complex. The reaction barriers obtained for this complex, however, are well higher than those found for fatty acid decarboxylation by a P450 peroxygenase. ${ }^{[19]}$ As such, UndA is not as efficient and powerful an oxidant as a P450 peroxygenase, but will react slowly with fatty acid substrates. This is in agreement with experimental reports on UndA that reported slow turnover reactions wit fatty acids.

\section{Conclusions}

In this work a computational study on the 1-undecene biosynthesis enzyme UndA is reported. Recent experimental studies created a controversy whether UndA has a mononuclear or binuclear iron active site. To investigate this, we created active site models of UndA based on the crystal structure coordinates of $4 \mathrm{WX} 0$. Our studies show that mononuclear iron(III)-superoxo models of UndA are sluggish oxidants that react via very high hydrogen atom abstraction barriers at room temperature. Consequently, mononuclear iron centers in the UndA structure are unlikely to react with fatty acids at room temperature. We then created a hypothetical diiron(IV)-dioxo structure using the crystal structure coordinates of UndA as a template. This model gives substantially lower hydrogen atom abstraction barriers; although it will be a slow oxidant at room temperature. Overall, our studies support the hypothesis of Makris et $\mathrm{al}^{\left[{ }^{13]}\right]}$ that UndA is a most likely a dinuclear iron system that reacts with dioxygen and fatty acids by decarboxylation of the substrate.

\section{Experimental Section}

Calculations were done using density functional theory methods as implemented in the Gaussian-09 and Orca software packages. ${ }^{[30]}$ In previous work we extensively tested and benchmarked models and methods for nonheme iron systems and reproduced experimental structures, spectroscopic parameters and rate constants well. ${ }^{[1]}$ Hence, most methods follow those recommended from previous work. Here we started our work from the $4 \mathrm{WXO}$ protein databank file, ${ }^{[9]}$ which is an enzyme monomer with substrate and dioxygen bound. A cluster model was created from the active site structure of the $4 \mathrm{WXO}$ pdb with residues selected as described in Scheme 1 above. We initially ran calculations with several constraints on amino acid residues to keep them close to the crystal structure positions. However, in a second set of calculations all constraints were released. As little geometric differences between the two structures were obtained, the final set of calculations was done without constraints.

Initial calculations used the unrestricted B3LYP hybrid density functional method ${ }^{\left[{ }^{[32]}\right.}$ in combination with a basis set containing an LANL2DZ + ECP on iron and 6-31G on the rest of the atoms (basis set BS1). ${ }^{[3]}$ Full geometry optimization and frequencies were run on all structures at UB3LYP/BS1 in the gas-phase. Subsequent single point calculations with the polarized continuum model (CPCM) were performed with a dielectric constant mimicking ethylphenylether, ${ }^{[34]}$ and a triple- $\zeta$ quality basis set (Basis set BS2): $\mathrm{LACV} 3 \mathrm{P}++\mathrm{ECP}$ on iron and $6-311+\mathrm{G}^{*}$ on the rest of the atoms. Calculations on the diron system use an LACVP (with core potential) on both iron atoms and $6-31 \mathrm{G}^{*}$ on the rest of the atoms for geometry optimizations, frequencies, intrinsic reaction coordinate and constraint geometry scans. All structures reported in this work are the result of a full geometry optimization without constraints and structures were characterized as a local minimum using a frequency calculation that gave real frequencies only (local minima) or a single imaginary mode for the correct displacement (transition states). For several transition states they were further confirmed by intrinsic reaction coordinate scans that linked them to reactants and products. All structures were considered in several low-lying spin state surfaces as identified with a superscript before the label.

The methods and procedures used in this work were tested and validated for analogous iron(IV)-oxo oxidants against experimental rate constants for oxygen atom transfer. ${ }^{[31,35]}$ These studies identified B3LYP as one of the best methods to reproduce reaction rates and selectivities. Furthermore, dispersion corrected DFT was shown to underestimate oxygen atom transfer reactions systematically and hence was not used for our calculations presented here. As the choice of the density functional method can occasionally affect spin-state orderings and relative energies we did some additional test calculations, which are described in the Supporting Information. ${ }^{[36]}$ Thus, the effect of dispersion on the spin-state ordering and reaction barriers was tested and ${ }^{3,5,7} \mathbf{R e}_{\mathrm{B}}$ and the reaction pathway via ${ }^{5} \mathbf{T S}_{\mathrm{B}, \beta}$ was reoptimized with B3LYPD3. ${ }^{[32,37]}$ As follows dispersion destabilizes the quintet spin state but the overall hydrogen atom abstraction barrier stays the same and the conclusions that mononuclear iron(III)-superoxo is a weak oxidant for hydrogen atom abstraction reactions is supported. We also explored the OPBE ${ }^{[38]}$ density functional method and although it stabilizes the triplet spin reactants, the quintet-septet energy gap remains the same (Supporting Information Table S12 and Figure S18). To further ascertain that the basis set core potential does not affects the spin state ordering, we reoptimized ${ }^{3,5,7} \mathbf{R e}_{\mathrm{B}}$ with UB3LYP/BS1 (without ECP) and although the triplet and quintet spin states are lowered by a few kcal mol ${ }^{-1}$ no changes in reaction mechanism are expected (Supporting Information Table S13 and Figure S19).

\section{Acknowledgements}

AS thanks Erasmus+ for an exchange studentship. YM thanks Learning Through Research for Summer Placement funding.

Keywords: nonheme iron • dioxygenase $\cdot$ decarboxylation • density functional theory $\bullet$ reaction mechanism

[1] a) E. I. Solomon, T. C. Brunold, M. I. Davis, J. N. Kemsley, S.-K. Lee, N. Lehnert, F. Neese, A. J. Skulan, Y.-S. Yang, J. Zhou, Chem. Rev. 2000, 100, 235-349; b) T. D. H. Bugg, Curr. Opin. Chem. Biol. 2001, 5, 550555; c) M. J. Ryle, R. P. Hausinger, Curr. Opin. Chem. Biol. 2002, 6, 193-201; d) M. Costas, M. P. Mehn, M. P. Jensen, L. Que Jr, Chem. Rev. 2004, 104, 939-986; e) M. M. Abu-Omar, A. Loaiza, N. Hontzeas, Chem. Rev. 2005, 105, 2227-2252; f) C. Krebs, D. G. Fujimori, C. T. Walsh, J. M. Bollinger Jr, Acc. Chem. Res. 2007, 40, 484-492; g) P. C. A. Bruijnincx, G. van Koten, R. J. M. Klein Gebbink, Chem. Soc. Rev. 2008, 37, 2716-2744.

[2] a) R. K. Bruick, S. L. McKnight, Science 2001, 294, 1337-1340; b) A Seifert, D. M. Katschinski, S. Tonack, B. Fischer, A. N. Santos, Chem. Res. Toxicol. 2008, 21, 341-348; c) C. J. Schofield, Z. Zhang, Curr. Opin. Struc. Biol. 1999, 9, 722-731; d) S. P. de Visser, Chem. Record 2018, 18, 1501-1516.

[3] a) K. Gorres, R. T. Raines, Crit. Rev. Biochem. Mol. Biol. 2010, 45, 106-124; b) M. A. McDonough, V. Li, E. Flashman, R. Chowdhury, C. 
Mohr, B. M. Lienard, J. Zondlo, N. J. Oldham, I. J. Clifton, J. Lewis, L. A McNeill, R. J. Kurzeja, K. S. Hewitson, E. Yang, S. Jordan, R. S. Syed C. J. Schofield, Proc. Natl. Acad. Sci. U. S. A. 2006, 103, 9814-9819.

[4] a) S. C. Trewick, T. F. Henshaw, R. P. Hausinger, T. Lindahl, B. Sedgwick, Nature 2002, 419, 174-178; b) P. Ø. Falnes, R. F. Johansen E. Seeberg, Nature 2002, 419, 178-182; c) P. J. O'Brien, Chem. Rev. 2006, 106, 720-752; d) C. Yi, C. G. Yang, C. He, Acc. Chem. Res. 2009, 42, 519-529.

[5] a) C. J. Schofield, Z. Zhang, Curr. Opin. Struc. Biol. 1999, 9, 722-731; b) M. D. White, E. Flashman, Curr. Opin. Chem. Biol. 2016, 31, 126135; c) C. Li, S. Liu, X. Yao, J. Wang, T. Wang, Z. Zhang, P. Zhang, K. Chen, Plant Growth Regul. 2017, 83, 489-500.

[6] a) L. Que Jr, Nat. Struct. Biol. 2000, 7, 182-184; b) E. G. Kovaleva, J. D. Lipscomb, Nat. Chem. Biol. 2008, 4, 186-193.

[7] a) B. J. Landgraf, S. J. Booker, J. Am. Chem. Soc. 2016, 138, 2889 2892; b) R. Rohac, P. Amara, A. Benjdia, L. Martin, P. Ruffié, A. Favier, O. Bertreau, J.-M. Mouesca, J. C. Fontecilla-Camps, Y. Nicolet, Nature Chem. 2016, 8, 491-500; c) K. V. Goncharenko, A. Vit, W. Blankenfeldt, F. P. Seebeck, Angew. Chem. Int. Ed. 2015, 54, 2821-2824; d) K. V. Goncharenko, F. P. Seebeck, Chem. Commun. 2016, 52, 1945-1948.

[8] a) M. H. Stipanuk, Annu. Rev. Nutr. 2004, 24, 539-577; b) G. D. Straganz, B. Nidetzky, ChemBioChem. 2006, 7, 1536-1548; c) C. A Joseph, M. J. Maroney, Chem. Commun. 2007, 3338-3349; d) S. Aluri, S. P. de Visser, J. Am. Chem. Soc. 2007, 129, 14846-14847; e) D. Buongiorno, G. D. Straganz, Coord. Chem. Rev. 2013, 257, 541-563; f) E. P. Tchesnokov, M. Fellner, E. Siakkou, T. Kleffmann, L. W. Martin, S. Aloi, I. L. Lamont, S. M. Wilbanks, G. N. L. Jameson, J. Biol. Chem. 2015, 290, 24424-24437

[9] Z. Rui, X. Li, X. Zhu, J. Liu, B. Domigan, I. Barr, J. H. D. Cate, W. Zhang, Proc. Natl. Acad. Sci. USA 2014, 111, 18237-18242.

[10] a) J. E. Baldwin, M. Bradley, Chem. Rev. 1990, 90, 1079-1088; b) P. L. Roach, I. J. Clifton, C. M. H. Hensgens, N. Shibata, C. J. Schofield, J. Hajdu, J. E. Baldwin, Nature 1997, 387, 827-830; c) M. Lundberg, P. E. M. Siegbahn, K. Morokuma, Biochemistry 2008, 47, 1031-1042; d) L. A McNeill, T. J. N. Brown, M. Sami, I. J. Clifton, N. I. Burzlaff, T. D. W. Claridge, R. M. Adlington, J. E. Baldwin, P. J. Rutledge, C. J. Schofield, Chem. Eur. J. 2017, 23, 12815-12824; e) E. Tamanaha, B. Zhang, Y Guo, W.-c. Chang, E. W. Barr, G. Xing, J. St. Clair, S. Ye, F. Neese, J. M. Bollinger Jr., C. Krebs, J. Am. Chem. Soc. 2016, 138, 8862-8874.

[11] a) M. C. Pirrung, Acc. Chem. Res. 1999, 32, 711-718; b) Z. Zhang, J. S. Ren, I. J. Clifton, C. J. Schofield, Chem. Biol. 2004, 11, 1383-1394.

[12] a) J. R. O'Brien, D. J. Schuller, V. S. Yang, B. D. Dillard, W. N Lanzilotta, Biochemistry 2003, 42, 5547-5554; b) M. K. Koski, R. Hieta, M. Hirsilä, A. Rönkä, J. Myllyharju, R. K. Wierenga, J. Biol. Chem. 2009 284, 25290-25301; c) H. M. Berman, J. Westbrook, Z. Feng, G. Gilliland, T. N. Bhat, H. Weissig, I. N. Shindyalov, P.E. Bourne. Nucl. Acids Res. 2000, 28, 235-242.

[13] O. M. Manley, R. Fan, Y. Guo, T. M. Makris, J. Am. Chem. Soc. 2019 , 141, 8684-8688.

[14] a) M. R. A. Blomberg, T. Borowski, F. Himo, R. Z. Liao, P. E. M. Siegbahn, Chem. Rev. 2014, 114, 3601-3658; b) M. G. Quesne, T. Borowski, S. P. de Visser, Chem. Eur. J. 2016, 22, 2562-2581.

[15] a) A. Wójcik, E. Broclawik, P. E. M. Siegbahn, T. Borowski, Biochemistry 2012, 51, 9570-9580; b) E. A. C. Bushnell, G. B. Fortowsky, J. W. Gauld, Inorg. Chem. 2012, 51, 13351-13356; c) S. P. de Visser, Chem. Commun. 2007, 171-173; d) X. Wang, H. Su, Y. Liu, Phys. Chem. Chem. Phys. 2017, 19, 7668-7677; e) H. Su, X. Sheng, W. Zhu, G. Ma, Y. Liu, ACS Catal. 2017, 7, 5534-5543; f) X. Song, J.Lu, W. Lai, Phys. Chem. Chem. Phys. 2017, 19, 20188-20197; g) N. Zeb, M. H. Rashid, M. Q. E. Mubarak, S. Ghafoor, S. P. de Visser, J. Inorg. Biochem. 2019, 198, 110728.

[16] D. Kumar, W. Thiel, S. P. de Visser, J. Am. Chem. Soc. 2011, 133 3869-3882.

[17] a) M. A. Rude, T. S. Baron, S. Brubaker, M. Alibhai, S. B. Del Cardayre, A. Schirmer, Appl. Environ. Microbiol. 2011, 77, 1718-1727; b) Y. Liu, C. Wang, J. Yan, W. Zhang, W. Guan, X. Lu, S. Li, Biotechnol. Biofuels 2014, 7, 28-40; c) J. Belcher, K. J. McLean, S. Matthews, L. S Woodward, K. Fisher, S. E. J. Rigby, D. R. Nelson, D. Potts, M. T. Baynham, D. A. Parker, D. Leys, A. W. Munro, J. Biol. Chem. 2014,
289, 6535-6550; d) A. Dennig, M. Kuhn, S. Tassoti, A. Thiessenhusen, S. Gilch, T. Bülter, T. Haas, M. Hall, K. Faber, Angew. Chem. Int. Ed 2015, 54, 8819-8822; e) J. L. Grant, C. H. Hsieh, T. M. Makris, J. Am. Chem. Soc. 2015, 137, 4940-4943

[18] a) B. Meunier, S. P. de Visser, S. Shaik, Chem. Rev. 2004, 104, 39473980; b) W. Nam, Acc. Chem. Res. 2007, 40, 522-531; c) Y. Watanabe, H. Nakajima, T. Ueno, Acc. Chem. Res. 2007, 40, 554-562; d) J. Rittle, M. T. Green, Science 2010, 330, 933-937.

[19] A. S. Faponle, M. G. Quesne, S. P. de Visser, Chem. Eur. J. 2016, 22, 5478-5483.

[20] M. Pickl, S. Kurakin, F. G. Cantú Reinhard, P. Schmid, A. Pöcheim, C K. Winkler, W. Kroutil, S. P. de Visser, K. Faber, ACS Catal. 2019, 9 565-577.

[21] a) E. Godfrey, C. S. Porro, S. P. de Visser, J. Phys. Chem. A 2008, 112 2464-2468; b) A. R. Diebold, C. D. Brown-Marshall, M. L. Neidig, J. M Brownlee, G. R. Moran, E. I. Solomon, J. Am. Chem. Soc. 2011, 133, 18148-18160; c) G. Dong, S. Shaik, W. Lai, Chem. Sci. 2013, 4, 3624 3635; d) A. Wójcik, M. Radoń, T. Borowski, J. Phys. Chem. A 2016 120, 1261-1274; e) A. Timmins, N. J. Fowler, J. Warwicker, G. D. Straganz, S. P. de Visser, Front. Chem. 2018, 6, 513.

[22] a) D. Kumar, H. Hirao, L. Que Jr., S. Shaik, J. Am. Chem. Soc. 2005 127, 8026-8027; b) S. P. de Visser, Angew. Chem. Int. Ed. 2006, 45, 1790-1793; c) C. Geng, S. Ye, F. Neese, Angew. Chem. Int. Ed. 2010, 49, 5717-5720; d) S. Ye, F. Neese, Proc. Natl. Acad. Sci. USA 2011,108, 1228-1233; e) L. Bernasconi, E. J. Baerends, J. Am. Chem. Soc. 2013, 135, 8857-8867; f) A. Timmins, M. G. Quesne, T. Borowski, S. P. de Visser, ACS Catal. 2018, 8, 8685-8698.

[23] a) S. Shaik, D. Kumar, S. P. de Visser, J. Am. Chem. Soc. 2008, 130 10128-10140; b) M. G. Quesne, D. Senthilnathan, D. Singh, D. Kumar P. Maldivi, A. B. Sorokin, S. P. de Visser, ACS Catal. 2016, 6, 22302243

[24] a) H. Hirao, K. Morokuma, J. Am. Chem. Soc. 2011, 133, 14550 14553; b) S. C. Peck, H. A. Cooke, R. M. Cicchillo, P. Malova, F. Hammerschmidt, S. K. Nair, W. A. van der Donk, Biochemistry 2011, 50, 6598-6605; c) L. Du, J. Gao, Y. Liu, D. Zhang, C. Liu, Org. Biomol. Chem. 2012, 10, 1014-1024.

[25] M. Lundberg, T. Kawatsu, T. Vreven, M. J. Frisch, K. Morokuma, J. Chem. Theory Comput. 2009, 5, 222-234.

[26] a) R. Latifi, M. Bagherzadeh, S. P. de Visser, Chem. Eur. J. 2009, 15, 6651-6662; b) R. Nath Manna, T. Malakar, B. Jana, A. Paul, ACS Catal. 2018, 8, 10043-10050; c) S. Álvarez-Barcia, J. Kästner, J. Phys. Chem. B 2017, 121, 5347-5354.

[27] M. Lundberg, P. E. M. Siegbahn, K. Morokuma, Biochemistry 2008, 47, 1031-1042

[28] a) X.-X. Li, V. Postils, W. Sun, A. S. Faponle, M. Solà, Y. Wang, W. Nam, S. P. de Visser, Chem. Eur. J. 2017, 23, 6406-6418; b) G. Mukherjee, A. Alili, P. Barman, D. Kumar, C. V. Sastri, S. P. de Visser Chem. Eur. J. 2019, 25, 5086-5098; c) P. Barman, F. G. Cantú Reinhard, U. K. Bagha, D. Kumar, C. V. Sastri, S. P. de Visser, Angew. Chem. Int. Ed. 2019, 58, 10639-10643.

[29] a) A. Timmins, M. Saint-André, S. P. de Visser, J. Am. Chem. Soc 2017, 139, 9855-9866; b) A. S. Faponle, F. P. Seebeck, S. P. de Visser, J. Am. Chem. Soc. 2017, 139, 9259-9270.

[30] a) Gaussian-09, Revision C.01, M. J. Frisch, G. W. Trucks, H. B Schlegel, G. E. Scuseria, M. A. Robb, J. R. Cheeseman, G. Scalmani, V. Barone, B. Mennucci, G. A. Petersson, H. Nakatsuji, M. Caricato, X Li, H. P. Hratchian, A. F. Izmaylov, J. Bloino, G. Zheng, J. L. Sonnenberg, M. Hada, M. Ehara, K. Toyota, R. Fukuda, J. Hasegawa M. Ishida, T. Nakajima, Y. Honda, O. Kitao, H. Nakai, T. Vreven, J. A Montgomery, Jr., J. E. Peralta, F. Ogliaro, M. Bearpark, J. J. Heyd, E. Brothers, K. N. Kudin, V. N. Staroverov, T. Keith, R. Kobayashi, J. Normand, K. Raghavachari, A. Rendell, J. C. Burant, S. S. Iyengar, J. Tomasi, M. Cossi, N. Rega, J. M. Millam, M. Klene, J. E. Knox, J. B Cross, V. Bakken, C. Adamo, J. Jaramillo, R. Gomperts, R. E. Stratmann, O. Yazyev, A. J. Austin, R. Cammi, C. Pomelli, J. W. Ochterski, R. L. Martin, K. Morokuma, V. G. Zakrzewski, G. A. Voth, P Salvador, J. J. Dannenberg, S. Dapprich, A. D. Daniels, O. Farkas, J. B Foresman, J. V. Ortiz, J. Cioslowski, D. J. Fox, Gaussian, Inc., 
Wallingford CT, 2010; b) F. Neese, WIREs Comput. Mol. Sci. 2018 8,e1327, doi:10.1002/wcms.1327.

[31] a) S. Kumar, A. S. Faponle, P. Barman, A. K. Vardhaman, C. V. Sastri, D. Kumar, S. P. de Visser, J. Am. Chem. Soc. 2014, 136, 1710217115; b) F. G. Cantú Reinhard, A. S. Faponle, S. P. de Visser, J. Phys. Chem. A 2016, 120, 9805-9814.

[32] a) A. D. Becke, J. Chem. Phys. 1993, 98, 5648-5652; b) C. Lee, W Yang, R. G. Parr, Phys. Rev. B 1988, 37, 785-789

[33] a) P. J. Hay, W. R. Wadt, J. Chem. Phys. 1985, 82, 270-283; b) W. J. Hehre, R. Ditchfield, J. A. Pople, J. Chem. Phys. 1972, 56, 2257-2261.

[34] J. Tomasi, B. Mennucci, R. Cammi, Chem. Rev. 2005, 105, 2999-3009.

[35] a) K. Cheaib, M. Q. E. Mubarak, K. Sénéchal-David, C. Herrero, R. Guillot, M. Clémancey, J.-M. Latour, S. P. de Visser, J.-P. Mahy, F. Banse, F. Avenier, Angew. Chem. Int. Ed. 2019, 58, 854-858; b) G.
Mukherjee, A. Alili, P. Barman, D. Kumar, C. V. Sastri, S. P. de Visser, Chem. Eur. J. 2019, 25, 5086-5098; c) S. Pattanayak, F. G. Cantú Reinhard, A. Rana, S. S. Gupta, S. P. de Visser, Chem. Eur. J. 2019 25, 8092-8104.

[36] a) H. Paulsen, L. Duelund, H. Winkler, H. Toftlund, A. X. Trautwein, Inorg. Chem. 2001, 40, 2201-2203; b) M. Güell, M. Solà, M. Swart Polyhedron 2010, 29, 84-93; c) M. Güell, J. M. Luis, M. Solà, M. Swart J. Phys. Chem. A 2008, 112, 6384-6391.

[37] S. Grimme, J. Antony, S. Ehrlich, H. Krieg, J. Chem. Phys. 2010, 132 154104.

[38] a) N. C. Handy, A. J. Cohen, Mol. Phys. 2001, 99 (2001) 403-412; b) J. P. Perdew, K. Burke, M. Ernzerhof, Phys. Rev. Lett. 1996, 77, 38653868. 
Entry for the Table of Contents (Please choose one layout)

Layout 1:

\section{FULL PAPER}

Text for Table of Contents

((Insert TOC Graphic here: $\max$. width: $5.5 \mathrm{~cm}$; max. height: $5.0 \mathrm{~cm})$ )

Author(s), Corresponding Author(s)*

Page No. - Page No.

Title

Layout 2:

\section{FULL PAPER}
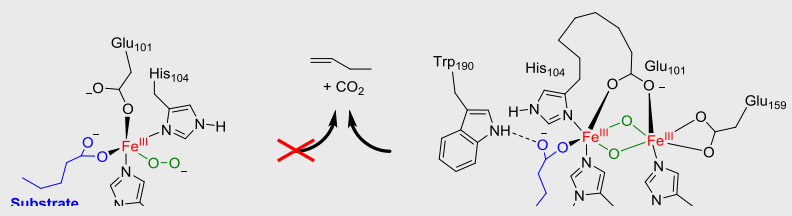

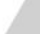

A comparison of mononuclear iron(III)-superoxo and diiron-dioxo models of the biofuel synthesizing enzyme UndA show that it is unlikely to be a mononuclear nonheme iron enzyme as high barriers for hydrogen atom abstraction are obtained. For the corresponding diiron-dioxo model; however, much lower barriers are found and hence is a more likely oxidant.
Yen-Ting Lin, Agnieszka Stańczak, Yulian Manchev, Grit D. Straganz, and Sam P. de Visser*

Page No. - Page No.

Can a mononuclear iron(III)-superoxo active site catalyze the decarboxylation of dodecanoic acid in UndA to produce biofuels? 